\title{
Reducing concentrations of trace metals in runoff waters from a vineyard catchment by way of an hybrid constructed wetland
}

\author{
B. MARIN ${ }^{1 *}$, A. CANER-CHABRAN ${ }^{1}$, S. DOUSSET $^{2}$, \\ A. CONREUX ${ }^{1}$, J. JAUNAT ${ }^{1}$, J. HUBERT ${ }^{1}, \mathrm{M}$.

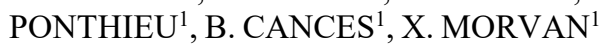 \\ ${ }^{1}$ GEGENAA, EA 3795, University of Reims-Champagne- \\ Ardenne, 51100 Reims, France \\ (*correspondence: beatrice.marin@univ-reims.fr) \\ ${ }^{2}$ LIEC, UMR CNRS 7360, University of Lorraine, BP \\ 70239, 54506 Vandoeuvre-lès-Nancy Cedex, France
}

The high slopes of the Champagne vineyard favor transfer of contaminants (used against vine deseases as $\mathrm{Cu}$ and $\mathrm{Zn}$ ) towards the surface water bodies by runoff and soil erosion. Constructed wetlands $(\mathrm{CW})$ are installed at the outlet of the vineyard watersheds to manage runoff waters and diffuse pollution. An hybrid CW was built at Nogent-l'Abbesse (East of Reims, France) to catch the runoff waters of a watershed of 176 ha area, including 95 ha of vines. This $\mathrm{CW}$ of $28000 \mathrm{~m}^{3}$ consisted of four remediation units dedicated to (1) decantation, (2) photodegradation, (3) phytoremediation and (4) infiltration. The aim of this study was (i) to assess the global efficiency of the $\mathrm{CW}$ for reducing the concentrations of trace metals in surface waters and (ii) to evaluate the effectiveness of each unit to understand the relative contribution of the bio-physico-chemical processes involved.

The flow rates were measured continuously and water samples were automatically collected at the inlet and outlet of each unit during 20 runoff events from November 2016 to November 2017. Trace metals were determined in the liquid phase and suspended matter after filtration of water samples.

The measured effectiveness of the $\mathrm{CW}$ was higher than $99 \%$ for $\mathrm{Cu}$ and $\mathrm{Zn}$ (near $100 \%$ for particulate phase and around $85 \%$ for dissolved phase) The decantation and photodegradation units were the most efficient (62-69\% and $24-27 \%$, respectively) for reducing concentrations of $\mathrm{Cu}$ and $\mathrm{Zn}$ in the particulate phase. For the concentrations in the dissolved phase, the decantation and phytoremediation units were the most effective (37-43\% and $22-45 \%$, respectively). The sand filter located at the inlet of the infiltration unit showed little efficiency $(<2.5 \%$ and $0.4 \%$ for particulate and dissolved phases, respectively). These efficiency values depended on the hydraulic residence time in each unit, governing the decantation and adsorption processes, and the absorption by plants. 